\title{
TRANSLATION OF CHINESE XIEHOUYU (SAYINGS) AND RELEVANCE THEORY
}

\section{CHIUNG-WEN LIU AND GRACE QIAO ZHANG}

\author{
Department of Foreign Languages \\ Shu-zen College of Medicine and Management \\ 452 Huangiu Rd, Luzhu, Shiang, Kaohsiung County 821, Taiwan \\ Phone: +64 9 7-6979333 ext: 1114 \\ E-mail: felicia@szmc.edu.tw \\ Department of Languages and Intercultural Education \\ Curtin University of Technology, GPO BOX U1987 \\ Perth, WA 6845, Australia \\ Phone: + 61892663478 \\ E-mail: Grace.Zhang@exchange.curtin.edu.au
}

\begin{abstract}
This study pioneers in applying the relevance theoretical framework developed by Gutt (1991, 2000a) and based on Sperber and Wilson's relevance theory $(1986,1995)$ to Chinese xiehouyu translations. A Chinese xiehouyu is an idiom or an enigmatic folk saying consisting of two parts. This study examines direct approaches and indirect approaches with or without the substitution of appropriate metaphors. It argues that while relevance theory is effective in both approaches, it is particularly important for indirect translation because there are various ways of translating a xiehouyu indirectly, depending upon what meaning aspects of the original the target audience will find relevant. A match-up metaphor in the target language may not always be available, but whenever possible the strategy of substituting metaphors should be utilised to maximise contextual effects and minimise the processing effort; this is probably the most effective way to achieve optimal relevance. As an instance of interpretive use, a translation's success depends on the achievement of optimal relevance. The translator has to pay attention to the kind and degree of interpretative resemblance the audience expects: that is to say, a translator should take the target audience's cognitive environment into account and choose the most applicable approach to guide the audience in achieving optimal relevance.
\end{abstract}

Key words: Chinese, translation, xiehouyu, relevance theory, linguistics,

\section{INTRODUCTION}

Chinese xiehouyu are unique and effective when used in Chinese language communication. While xiehouyu are extremely popular amongst Chinese people, 
few translators have attempted to translate them. There has been little research done on the translation of Chinese xiehouyu into English because of their complexity and the lack of a theoretical framework for the translation of such sayings.

This study explores the translation of Chinese xiehouyu into English within the theoretical framework of relevance theory. This theory was proposed by Sperber and Wilson $(1986,1995)$ and developed from an inferential model of communication and an effective description of the human communication process. Gutt (1991, 2000a) pioneered the application of relevance theory to translation and established it within a theoretical framework for translation.

A Chinese xiehouyu is defined as "a two-part allegorical saying, of which the first part, always stated, is descriptive, while the second part, sometimes stated, carries the message" (A Chinese-English Dictionary. Beijing Foreign Language Institute 1978: 762). Similarly, Cheung (1982) defines a xiehouyu as a type of idiom consisting of two parts separated from each other by a pause. The first part contains specific information and provides certain clues that lead to the 'answer', as the second part is known. For example,

\section{(1.1) 泥菩薩 過 江 --- 自身 難 保 \\ Ni puza guo jiang - zishen nan bao \\ clay idol ford river oneself difficult protect}

A clay idol fording a river, hardly able to save itself, let alone assist anyone else.

The first part provides an image of a clay idol crossing a river, which conveys the message of the second part: 'difficult to save anyone including itself'.

Xiehouyu embody the wit and sense of humour of Chinese people. They are commonly found in both written and spoken Chinese. There seems no complete equivalent use of xiehouyu in English; the most similar would be to say, 'Speak of the devil - and he will appear' or 'Touch wood - I hope it stays this way'. Rohsenow (1991) calls the xiehouyu an 'enigmatic folk simile', but this is too long to be used as its English name. Xiehouyu are unique, so in the present article the Chinese name is retained, when referring to this phenomenon.

A xiehouyu tends to be in the form of an elaborate metaphor. Normally the second phrase explains the intended meaning of the metaphor, often in a punning sense. This wordplay tends to add humour to the communication. For example: 
(1.2)

$\begin{array}{ll}\text { 孔夫子 搬家 } & - \text { 淨 是 書(輸) } \\ \text { Kong Fuzi ban jia } & - \text { jing shi shu. } \\ \text { The Confucius move house } & \text { all be book (homonym: to lose) } \\ \text { When Confucius moved house, all he had was books/ he lost everything. }\end{array}$

(1.2) utilises the metaphor of Confucius moving house, the pun of shu (書, book) and shu (輸, lose) to create humour and an unexpected message, because people do not necessarily connect the two. This kind of unexpected wordplay is unique and effective.

It is believed that xiehouyu originated from xiehoushi (歇後詩, xiehouyu poem) of the Tang Dynasty. The term xiehouyu was first explicitly referred to in A.D. 898 (Tang Dynasty) by Zheng Qing in the famous chronicle history book Old Tang Poem (Rohsenow 1991). Xiehouyu have been very popular in spoken language as part of the rich oral repertoire of the common Chinese people for centuries, and they play an indispensable role in communication (Rohsenow 1991). The contents of xiehouyu come from a variety of sources; they originate from daily life and from a wide range of artistic, mythological, religious, and superstitious common beliefs. They demonstrate the full colour of Chinese mythology, religion and custom, and convey complicated ideas effectively and humorously. For example:

\begin{tabular}{|c|c|c|}
\hline 黃鼠狼 & 拜 & 年 \\
\hline $\begin{array}{l}\text { Huangshulang gei ji } \\
\text { give chicken }\end{array}$ & $\begin{array}{l}\text { bai } \\
\text { make a courtesv call }\end{array}$ & $\begin{array}{l}\text { nian } \\
\text { New Year }\end{array}$ \\
\hline
\end{tabular}

\section{- 沒 安 好 心眼}

- mei an hao xinyanr not install good intention A weasel wishing Happy New Year ${ }^{3}$ to a chicken, harbours no good intentions

狗咬呂洞賓 - 不識好人 心

Gou yao Lü Dongbin - bu shi haoren xin dog bite proper name not recognise good person heart A dog biting Lü Dongbin, does not recognise a good hearted person.

The two approaches introduced by Gutt (1991, 2000a), direct and indirect translation, will be applied to xiehouyu translation to test whether relevance theory serves as an effective framework for xiehouyu translation. 


\section{THEORETOCAL BACKGROUND}

\subsection{Xiehouyu}

In China, research on xiehouyu has a history of more than seventy years. According to Wen and Zhou (1999), there have been three major phrases of xiehouyu research: 1930 to 1949,1949 to 1960, and since the 1960s. The first stage concentrated on the origin of xiehouyu, the second on the function of xiehouyu in communication, and the final stage, still ongoing, focuses on the linguistic features and functions of xiehouyu within a specific context.

The classical written form of Chinese was once regarded as the only prestigious literary language in Chinese and the only linguistic repertoire worthy of study. Under the influence of the Common Speech Movement in the 'May Fourth Period' (1919 to 1930s) the prestige of Classical Chinese changed. In the 1930s, scholars began to take an interest in the spoken form of Chinese (particularly vernacular folk sayings) and put much effort into researching this untouched field. As vernacular folk sayings, xiehouyu were studied extensively during the movement; the 1930s is regarded as the most vigorous and fruitful era for xiehouyu research (Yu 2000).

Among the researchers of Chinese xiehouyu, Chen Wangdao is one of the most influential scholars in China. In Chen's famous book, Introduction to Rhetoric, xiehouyu are classified as cangci (藏詞, hidden words) as part of Chinese rhetoric (1962:159). Chen gives a comprehensive linguistic analysis of xiehouyu and divides them into two types. The first is the old type of xiehouyu, with the last character of a fused phrase idiom omitted in order to call it to mind, often in a form of a homonym to create a punning sense. With richer content and more natural form, the second is a new type of xiehouyu developed from the old one. It has two parts; if one part is omitted, the other is still syntactically independent. The part omitted or suppressed is not likely to be simply one character, as in the old type, but rather several words embedded in a syntactical construction. Chen's analysis of xiehouyu, influential and highly regarded by Chinese scholars, has laid a good foundation for future xiehouyu study (Wen and Zhou 1999).

\subsection{Gutt's Framework}

Based on the inferential communication model proposed by Grice (1975), Sperber and Wilson $(1986,1995)$ developed the relevance theory. Its purpose is to explain the process of human cognition and communication in real-world situations. The principle of relevance is that every act of ostensive communication also 
communicates a presumption of its own optimal relevance. In other words, in every communication, communicators claim that they are searching for the most relevant method of presenting information (i.e. optimal relevance) in the audience's own cognitive environment, compatible with their abilities and preferences. If the information provides sufficient relevance to the audience (i.e. yields the most contextual effects), the audience can process it with the least processing effort and achieve optimal relevance. This concept is regarded as the essential mechanism for successful communication.

Working as a Bible translator for several years, Gutt saw a lack of development in the area of psychological cognition in the translation process. Consequently, the mental processes utilised by a translator by which $\mathrm{s} /$ he decided to explicate an implicit linguistic use (e.g. irony and metaphor) in a source language text remained a mystery. Inadequate use of cognitive theory in translation studies may reduce the effectiveness of translation practice. Understanding the importance of human cognition in translation practice and the need to build up a cognitive theoretical framework for translation, Gutt proposed the relevance theoretical framework.

The fundamental belief of Gutt's theoretical framework is that translation is "an act of communication across language boundaries", and a successful translation yields a successful communication. Gutt claims that "since the phenomena of translation can be accounted for by this general theory of ostensive-inferential communication, there is no need to develop a separate theory of translation" (Gutt 2000a:199), as relevance theory provides sufficient guidelines and principles for successful translation.

Gutt's approach to translation has provoked widespread debate from translation theorists. Responses are sharply divided into two groups, ranging from supportive (Frawley 1992, Hymes 1992, Salkie 1991, Wickler and Van Der Merwe 1993) to critical (Fawcett 1997, Malmkjær 1992, Wendland 1996). Salkie (1991) praises Gutt's approach as wise and right, and as no small achievement in the development of translation theory because it "explains something genuinely new and useful about translation" (Salkie 1991). Generally speaking, scholars appreciate this approach because it is an improvement over previous code-model based theories. It provides a deeper understanding of the translation process, so that translators can adopt appropriate strategies for the problems they encounter (Wickler and Van Der Merwe 1993).

The most common criticism elicited by Gutt's approach is its vagueness and lack of practical value to translators. Malmkjær says that "if translators want direct help with their everyday concerns, they should not expect to find it here" (1992:306). Wendland (1996) also thinks that relevance theory is a vague concept, which provides translators no concrete help in making translation decisions and evaluating the faithfulness of translated text. Similarly, Fawcett (1997:139) 
considers the approach as "another theory about translation and translator behaviour that has been deductively arrived at from general principles rather than inductively from empirical data", and which therefore, has no practical value.

In response to these critiques, Gutt explains that the purpose of relevance translation theory is to help translators have a better understanding of translation problems, rather than to provide any rules. It serves as a "prerequisite for the proper application of any rules and principles of translation $\mathrm{s} / \mathrm{he}$ might come across" (Gutt 2000a:224), so that "the translator knows how to make a decision in all those instances for which no rules or guidelines exist" (Gutt 2000a:227).

With translation as an instance of interpretive use, Gutt (1991/2000a, Ch.7) emphasizes that the success of a translation is not measured by the achievement of optimal relevance alone; it is also crucial for the translator to take into account the kind and degree of interpretative resemblance which the audience expects.

Within the relevance theoretic framework, translators should consider the meanings conveyed in the source text, and the contextual background within which an utterance is intended to be interpreted, as well as the cognitive environment of the target audience. Thus, when the translator makes decisions, $\mathrm{s} /$ he will take the target audience's background knowledge and particular interests into consideration and produce an interpretation that will help the target audience achieve communication success.

What follows is a detailed discussion on relevance theory in relation to Chinese xiehouyu translation which establishes that it does provide an effective theoretical framework for Chinese xiehouyu translation. It should be emphasized that the significance of Gutt's approach is its practicality as a type of communication. It does not offer more to the practice of translation than previous translation theories, including functional theories of translation which emphasize the importance of the audience and the audience's contextual background, and the like. The principle of relevance is more significant from a theoretical than from a practical point of view.

\section{RELEVANCE THEORY AND TRANSLATION}

Relevance theory fills an important niche in translation. In this section, the relevance theoretical framework and its benefits to translation will be discussed in detail. 


\subsection{Communication in the Relevance Theoretical Framework}

Relevance theory is developed upon an inferential model ${ }^{5}$ of human communication as a cognitive theory. According to relevance theory, in communication a communicator produces some kind of 'stimulus', from which the audience infers two important thoughts. The first thought is that the communicator has the intention to communicate with him/her, referred to as the communicative intention of a communicator. The second is that there is information the communicator intends to communicate, referred to as the informative intention of a communicator. Communication containing a communicative intention and an informative intention is referred to as ostensive-inferential communication. Human communication is ostensive-inferential in nature. When the audience infers the intended information of the communicator, this communication is successful (Sperber and Wilson 1986, 1995). Communication failure happens when the audience infers the wrong informative intention of the communicator. Therefore, inference is fundamental to human communication and the key to communication success is to have the correct inference. The only way for an audience to discern a correct inference is through the assumption of relevance. Sperber and Wilson $(1986,1995)$ define the relevance of particular assumptions (i.e. of beliefs, thoughts, or propositions) in particular contexts:

(a) An assumption is relevant to the extent that its contextual effects in a context are large.

(b) An assumption is relevant in a context to the extent that the effort required to process it in this context is small.

In other words, an utterance must link up with its context to be considered relevant. In order to achieve this, the utterance must have adequate contextual effects and cost the audience the least processing effort. To explain the notion of contextual effect, the meaning of context in a relevance theoretical framework must be elaborated first. Context in relevance theory is not a linguistic but a psychological notion. It is regarded as "the set of premises used in the interpretation of an utterance" (Sperber and Wilson 1986:15).

In other words, context is not limited to linguistic co-texts, but also consists of expectations, scientific hypotheses or religious beliefs, anecdotal memories, general cultural assumptions, and beliefs about the mental state of the speaker. Context is the hearer's belief about the world, which consists of the hearer's cognitive environment (Gutt 1992). The notion contextual effect is context dependent, and serves as a modification of the audience's cognitive environment. 
In communication, "the more contextual effects an utterance achieves, the more relevant it will be to that audience" (Gutt 1992:24).

When an audience processes any information, s/he must spend mental effort. Normally this effort will be spent "for the linguistic decoding, the inferential processes, and for retrieving information from memory" (Gutt 1992:24). The more relevant the information to the audience, the less processing effort the audience will spend. On the other hand, the less contextual effects an utterance achieves with an audience, the less relevant it will be to the audience. "Thus, relevance is seen as the cost-benefit relation of processing effort spent versus contextual effect obtained" (Gutt 1992:24).

\subsection{Translation in a Relevance Theoretical Framework}

Translation is an act of human communication which has a common purpose: to communicate across language boundaries. As mentioned in the previous discussion, the success of communication depends on consistency with the principle of relevance; so the success of translation also depends on consistency with the principle of relevance.

\subsubsection{The Notion of Translation}

In the interpretive use of language, there is a relationship of interpretive resemblance between the original text and that used to represent it (Gutt 1998). Interpretive resemblance is achieved when two utterances share the same meaning properties, explicatures and implicatures. As an interpretive use of language, translation must interpretively resemble the source text. In other words, "translations are representations of texts in other languages and, in order to communicate successfully, these texts must be faithful representations of the originals" (Gutt 1992:42). Within the relevance theoretical framework, interpretive resemblance is the notion of faithfulness in translation.

Translation, as an interpretive use of language, must interpretively resemble the original to the degree that yields adequate contextual effects without costing the audience unnecessary processing effort. This is the relevance-based definition of faithfulness. However, translators often face a dilemma when the translation has a high degree of interpretive resemblance yet suffers a low degree of relevance to the target audience due to the increase in processing effort. In this case, it is suggested that the translator consider whether this high degree of resemblance is "outweighed by the gains of contextual effects" (Gutt 2000a:386). If not, 
translators should rather render their translations with less resemblance, in order to achieve a successful communication. Clearly, the notion interpretive resemblance is not absolute but relative: a translator is entitled to determine the degree of interpretive resemblance of a translated text in consistency with the principle of relevance.

\section{Position of translation}

within the relevance theoretical framework (Gutt, 2000a:214).

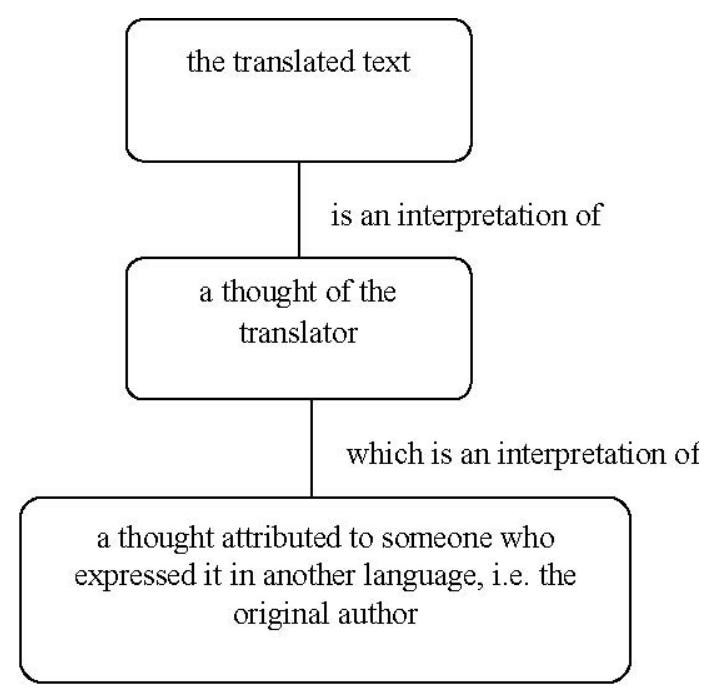

Translators often face the problem of secondary communication situations (Gutt 1991, 2000a). A secondary communication situation occurs when "one attempts to communicate a given informative intention to an audience other than the one for which this information was meant in the first place" (Gutt 1992: 27). In other words, translators attempt to communicate the informative intention of the source text's author to a target audience. However, this information is originally communicated to the source audience rather than to the target audience. Consequently, in the secondary communication situation, translation is an interpretive use of language, because it "is intended to restate in one language what someone else said or wrote in another language" (Gutt 1998: 46). As Gutt (1998) claims, translation is comparable to quoting or speech-reporting in intra-linguistic use. 


\subsubsection{Translator's Role}

In translation, the audience deals with the utterance made by a translator rather than by the source author: that is, they receive a translator's interpretations of the source text. Translation is therefore regarded as an act of communication between translators and the target audience and "translators are the actual communicators to the target audiences" (Gutt 2000a:215) In a relevance theoretical framework, translators play the main role in communication; their status has risen from invisibility to the spotlight. The first task of a translator is to focus on bringing out those assumptions from the original interpretation that would yield the maximum contextual effects in the cognitive environment s/he shares with the target audience, in order to achieve optimal relevance without costing audiences unnecessary processing effort (Gutt 2000a).

However, a translator also faces the difficulty that target audiences may have different expectations, cultural backgrounds and the like, and so from the same utterance, different audiences may yield different degrees of relevance and so produce different levels of contextual effect. A translator must use his knowledge of the audience... to make assumptions about its cognitive environment and about the potential relevance that any aspects of the interpretation would have in that cognitive environment (Gutt, 2000a). Thus, a translator makes a translation decision based on his/her beliefs about what will be the optimum relevance for the audience.

\subsubsection{Two Approaches in Translation Practice}

Direct and indirect translations are two approaches in the relevance theoretical framework. The illustration and detailed analysis of these two approaches will be carried out in Section four, in the setting of Chinese xiehouyu translations.

\section{A. Direct Translation}

Direct translation is seen as equivalent to direct quotation in intralingual usage. Gutt's definition argues that "A receptor-language utterance is a direct translation of a source-language utterance if, and only if, it presumes to interpretively resemble the original completely" (Gutt 1992:66).

Direct translation is regarded by Gutt as a special case of interpretive use. It aims to have a 'total interpretive resemblance' to the original text as well as preserving all the communicative clues of the original text. This type of translation, if achieved successfully, will be able to communicate the full intended 
interpretation of the original to the target audience. Furthermore, "the target-language text would display the target-language properties that correspond to the source-language properties of the original" (Gutt 1992:66). A direct translation gives the audience potential access to the authentic meaning of the original, and the influence of the translator's interpretation is minimised by reference to communicative clues.

When the target audience processes the direct translation using the contextual assumptions contained in the source text, s/he will be able to arrive at the originally intended interpretation. Direct translation therefore requires the target audience to familiarise themselves with the context envisaged for the original text, because this is the only way they may gain the authenticity of the original text that a direct translation promises (Gutt 1992).

\section{B. Indirect Translation}

Indirect translation, on the other hand, does not require the audience to be familiar with the original context, although it is also an instance of interpretive use. Indirect translation presumes adequate resemblance and only in relevant respects to the original text. In this approach, a translator tends to translate in a manner that provides the most accessible contextual information for the audience. The translator first obtains the intended interpretation of the original, then takes the audience's cognitive background into consideration and makes translation decisions consistent with the principle of relevance. As a result, the translator determines in what respects her/his translation should interpretively resemble the original so that the audience can achieve optimal relevance without spending unnecessary processing effort (Gutt 1990). Indirect translation includes a variety of strategies, including substitution of appropriate metaphors.

Within the relevance theoretical framework, a translator is the actual communicator of information. In order to spend the least effort, audiences rely on the translator's relevant interpretation to infer the intended information of the original text. The point of translation is to give access to an interpretation that resembles that of the original in relevant respects.

\section{APPLICATION OF RELEVANCE THEORY TO THE TRANSLATION OF CHINESE XIEHOUYU}

Having discussed relevance theory and its application to translation practice, in this section this framework will be applied to the translation of Chinese xiehouyu. Each phrase will be translated using both the direct and indirect approach, 
followed by an analysis. In order to provide an understanding of the Chinese xiehouyu, its linguistic characteristics will be explained first.

As mentioned in the introduction, xiehouyu are full of allusions, cultural elements and wordplay; such characteristics are vital to the satirical and humorous sense of xiehouyu. However, in translation these features are difficult to preserve with the same resemblance. Over the years few translators have attempted this difficult task. Indeed, at times Xiehouyu have been considered 'untranslatable', because, while denotational and explicit meanings may be conveyed accurately, connotational and implicit information (such as humour) may never be retained perfectly in the translated text.

The translation of Chinese xiehouyu can be traced back to the early 20th century. At that time, translations were being made of classical Chinese novels like the Story of the Stone ${ }^{10}$, The Scholars and Water Margin ${ }^{12}$. In these classic novels, the use of xiehouyu is not rare. One common strategy adopted by the translators when encountering xiehouyu was to offer a free translation (Bao and Bao 2001:159).

A systematic translation of Chinese xiehouyu was undertaken by Sun (1981). Aiming to help foreign students learning Chinese culture and language, Sun published one of the most important works for xiehouyu with non-native speakers in mind: As the Saying Goes. For each xiehouyu, phonemic transliteration is provided, followed by word-by-word analysis and literal and meaning translations. Furthermore, Sun uses long footnotes explaining the allusions or cultural elements contained in xiehouyu. Sun's in-depth work sets a milestone for xiehouyu translation.

Rohsenow (1991) published a Chinese-to-English xiehouyu dictionary. Rohsenow spent several years in China researching for this dictionary, and it is the fruit of many years' hard work. It has a comprehensive collection of xiehouyu, ranging from old sayings to current and newly created ones. Each xiehouyu is translated literally, followed by its intended meaning and supplementary information in brackets. In each entry, Rohsenow reduces the explanatory notes to a minimum, so readers may need to make more effort in discovering the background of each xiehouyu.

Steelman (1990) translated xiehouyu in a set of children's books, aiming to educate the younger generation of overseas Chinese. Each xiehouyu is translated literally in simple language. With the help of colourful pictorial illustration and explanatory notes, young readers need not make too much effort to process the extra background information.

One Hundred Chinese Two-Part Allegorical Sayings is a recent work in xiehouyu translation. It was published by Sinolingua in 1999 in a Chinese language education series. The purpose is to help foreign students get acquainted with Chinese culture and Chinese idiomatic usages. Similar to Steelman's work, 
the strategy is literal translation with pictures and minimum explanatory footnotes.

From these works it seems that literal translation with explanatory footnotes is a common strategy for Chinese xiehouyu translation. In more recent years, three different strategies have been promoted: literal translation, meaning translation, and substitution with equivalent metaphors (Bao and Bao 2001, Feng 2001, Shan 2001). The translator is encouraged to adopt the strategy best suited for the target audience.

\subsection{Linguistic Features of Chinese Xiehouyu}

As mentioned previously, xiehouyu generally have two phrases. The first phrase tends to be in the form of a metaphor, and is referred to as the 'cue phrase', providing a figurative cue for the listener. The second phrase may be implied and not appear at all, but if it does, it carries the intended message. The listener needs to infer from the first phrase the message, which is conveyed by the second phrase, referred to as the 'answer'.

In verbal use, a pause comes between the first and second phrase, which provides time for the hearer to infer the intended answer or to react to the hidden sense of humour. Normally the metaphorical first phrase can be understood easily, so the listener will have no trouble inferring the intended meaning. In many cases, the explanatory second phrase is suppressed, because the speaker expects that the listener will be able to understand the metaphorical first phrase.

In written form, the two phrases are normally separated by a dash. For example:

$$
\begin{aligned}
& \text { (4.1) 老牛 鑽窗眼 - 騙 人 } \\
& \text { Laoniu zuan chuang yan - pian ren } \\
& \text { ox break through window hole deceive }
\end{aligned}
$$

The following Chinese xiehouyu offers an example of the semantic content of the first phrase (the metaphor):

$\begin{array}{llll}\text { 花崗岩 } & \text { 腦袋 } & - \text { 頑固 } \quad \text { 不化 } \\ \text { Huagangyan } & \text { naodai } & - \text { Wangu buhua } \\ \text { granite } & \text { head } & \text { stubborn not melt } \\ \text { A granite head, absolutely stubborn. }\end{array}$


Metaphors in the first phrase normally appear as noun or verb phrases which provide a description of some sort.

(4.3) 泥菩薩

Ni Pusa

clay Boddhisattva cross river

身難 保

A clay Boddhisattva crossing a river, can't even save itself, let alone another.

Xiehouyu such as (4.3) have a strong cultural connotation, such as traditional Chinese customs, daily living, religion, or the like. Buddhism is a common faith for the Chinese; they worship and give offerings to the idol of Boddhisattva in the belief that he can give them peace, blessing and protection.

$$
\begin{aligned}
& \text { 王 莽 的 法令 }- \text { 天 三 改 } \\
& \text { Wang Mang de faling - yi tian san gai } \\
& \text { proper name particle decree one day three change } \\
& \text { Wang Mang's decree, changing three times a day. }
\end{aligned}
$$

Metaphors as in (4.4) contain an allusion based on well-known events or stories in Chinese history. Wang Mang was a usurper during the Han dynasty. He founded the Xin dynasty (A.D. 8-23), the shortest-lived dynasty in Chinese history. Wang Mang was notorious for his changeable legal codes.

\section{(4.5) 閻王爺出告示 - 鬼話連篇 \\ Yanwangye chu gaoshi- guihua lianpian \\ The Lord Yama put up proclamation ghostly words full of \\ The Lord Yama putting up a proclamation, full of ghostly words/absolutely rubbish.}

Metaphors as in (4.5) refer to folk legends, fairy tales or novels. In traditional Chinese belief, the Lord Yama reigns over hell as the God of Death. He has authority over ghosts, so his proclamations would be aimed at ghosts and full of ghostly words. Guihua in Chinese literally means ghostly words, with the 
connotation of 'unreal' or 'rubbish'. This xiehouyu is used to describe a situation where someone is talking a load of rubbish.

In terms of the linguistic features of the answer phrase of a xiehouyu, the following offer interesting examples:

$\begin{array}{lllll}\text { 逆 水 行 舟 }- \text { 不 進 } & \text { 則 } & \text { 退 } \\ \mathrm{Ni} & \text { shui xing zhou } & - \text { bu jin } & \text { ze } & \text { tui } \\ \text { against water sail boat } & \text { not proced then retreat }\end{array}$

A boat sailing against the current, forge ahead or be driven back.

Xiehouyu as in (4.6) have a second phrase which is a simple and straightforward explanation of the first, metaphorical, phrase.

(4.7) 八仙

Baxian

\section{過 海 - 各顯 神通}

guo hai - ge xian shentong

Eight Immortals cross sea each show theurgy

Like the Eight Immortals crossing the sea, each one showing his special prowess.

Xiehouyu as in (4.7) have a set phrase for the 'answer', a typical four-characterset Chinese idiom. This type of idiom is commonly used in Chinese language, full of historical colour and literary allusion including folk legends and fables.

In puns such as the one in (4.8), one character shares the same phonetic features with another one, but has a different semantic content. This type of pun functions as a humorous touch.

\subsection{Xiehouyu Translation}

With the use of metaphors and puns, xiehouyu are characterised by the figurative use of language and play on words. Gutt regards metaphors and puns as "nonliteral 
uses" (Gutt 1992:48), and as "stylistic properties" (Gutt 2000a:135) of a language. In relevance theory, Sperber and Wilson $(1986,1995)$ refer to the peculiar properties possessed by nonliteral uses of language as "poetic effects" ${ }^{14}$. In order to translate xiehouyu effectively, it is important to understand the essence of metaphors and puns as part of the relevance theoretical framework.

\subsubsection{The Essence of Metaphors and Guidelines for their Translation}

Lefevere (1992:37) states that metaphors function as "Concepts that do not normally belong together [but] are linked in such a way as to increase the illocutionary power of the passage, preferably without overly straining the reader's credulity or sense of propriety".

Sperber and Wilson $(1986,1995)$ distinguish metaphors from the literal use of language. Metaphors are characterised by the excessive implicit information contained in them. In communication, the audience, rather than the communicator, is held responsible for the interpretation of the metaphor. In other words, it is the audience's duty to distinguish which contextual implications are intended by the communicator and which are not, in order to achieve a successful communication. When the audience encounters a metaphor, s/he assumes that the two propositional forms (of the utterance and of the thought interpreted, respectively) contained in the metaphor must "have some identifiable logical and contextual implications in common" (Sperber and Wilson 1986:235). For example, in the metaphor 'John is a pig', John is assumed to share certain logical contextual similarities with a pig. The speaker assumes that the hearer will be able to distinguish the contextual implications shared by John and a pig (lazy, fat, dirty, etc.).

The hearer will continue to add contextual implications to the overall interpretation of the utterance until it is relevant enough to be consistent with the principle of relevance. As a result, s/he will be able to construct the right interpretive assumption about the speaker's informative intention, which is 'John is lazy' and the like, at which stage the communication is successful.

According to relevance theory, in metaphors the hearer is allowed to draw as many inferences as possible in order to obtain adequate contextual effects and achieve optimum relevance. However, not every metaphor is complicated or requires a high level of processing effort. There is a degree of communicative strength for implicatures in metaphors. Some implicatures are stronger and referred to as strong implicatures. Others may be comparatively weak, and are referred to as weak implicatures. In human thinking processes, the narrower the range of possible conclusions, the stronger the implicatures. 
Because metaphors with strong implicatures yield a narrow range of contextual effects, it costs the audience less processing effort to infer the intended information. Furthermore, an audience holds less responsibility for the validity of her/his interpretation and it is easier to reach optimum relevance. In contrast, metaphors with more, comparatively weak, implicatures have a wider range of possible conclusions. They yield more contextual effects and cost the audience more effort to explore the intended meanings of the communicator, and are therefore more creative. Furthermore, the audience bears more responsibility in constructing the true interpretation of the utterance, compared to interpreting metaphors with strong implicature. Respectively, the more creative metaphors make it harder for the audience to reach optimum relevance.

A successful metaphor translation must be consistent with the principle of relevance. A translator should aim to convey all the explicatures and implicatures of the metaphor and make sure they are optimally relevant to the target audience. However, to explicate every metaphor and paraphrase it clearly does not necessarily guarantee that the audience will obtain full understanding (of all the explicatures and implicatures) of the metaphor. Translators must remember that metaphors are not plain-language expressions; they are full of implicit information. Furthermore, the reason for using metaphors is that the communicators of the source text "must have intended to convey something which is more than a plain-language expression if the relative indirectness of the utterance is to be justified" (Sperber and Wilson 1986:51). Straightforward explication may not be the only or best solution for metaphor translation. There will always be "the danger of limitation and distortion that can arise from explication" (Gutt 1992:72).

However, to leave a metaphor implicit does not guarantee that the audience will obtain the perfect preservation of implicature, either. There are also certain implications of the original that are highly relevant to the source language audience but cannot be derived from the semantic content alone because of contextual differences. As a result, there are many ways in which the target language audience may acquire information, and it is not necessarily the translator's responsibility (Gutt 2000b).

The relationship between strength of communication, range of contextual effects and relative responsibility between communicator and audience shows that the key to communication success is to ensure that translated metaphors possess adequate contextual effects for the target language audience, and are communicable to them. 


\subsubsection{The Essence of Pun and Guidelines to Its Translation}

Lefevere has a comprehensive description of the essence of puns and their contribution to contextual effects in an utterance: "A pun is a play on two of the meanings a word can have. Because readers must make a conscious effort to distinguish between the different meanings of the word and to find out which one the author intends, the pun activates two meanings at the same time. Readers get both the obvious usual meaning of a word and the frequently less obvious, more unusual meaning the author intended. They get the 'norm' and the 'deviation' from the norm simultaneously. The clash between the two heightens the pun's illocutionary power" (1992:51-52).

In the relevance theoretical framework, a pun is a 'stylistic property' of a language. Puns possess linguistic features that tend to exist in one particular language only. In translation, where the target language has a totally different linguistic system from the original language, the same linguistic features may not be replicable. In other words, complete resemblance for puns may be impossible in the target language. Therefore, in many cases, puns in the original text are simply eliminated in the target language.

Gutt argues that "the point of preserving stylistic properties lies not in their intrinsic value, but rather in the fact that they provide clues that guide the audience to the interpretation intended by the communicator. We shall refer to such clues as communicative clues" (2000a:134). Puns provide clues about the intended information as well as offering humour. Their communicative value is the emphasis on the idea of play on words and the extra contextual effects they yield in an utterance. Puns increase the audience's processing effort to infer the intended meaning, which may be a less obvious, more unusual, meaning. In return for the extra expenditure of effort by the audience, the reward is the intended information and extra humour.

From the perspective of relevance theory, translations of puns must be consistent with the principle of relevance; that is, they must produce adequate contextual effects without creating unnecessary processing effort for the audience. The aim is not to preserve the specific linguistic forms or semantic representation of puns in the target language. Instead, the optimum goal of pun translation is to preserve the stylistic features which convey communicative clues. These features "reflect not only the information content of what was said, but also the way in which it was expressed and the special effects that such stylistic features would achieve" (Gutt 2000a:135), so a translator should aim for an interpretive resemblance of communicative clues for translating puns.

However, translators must also bear in mind that if their translation departs from the 'normal' linguistic structure of the target language, it may not increase the contextual effects of an utterance but instead face the risk of "failing to 
compensate that hearer's additional expenditure of effort....[and] to be awkward, unnatural"(Gutt 1992:58). A pun should never be translated unnaturally, that is, "requiring processing effort but without any reward in terms of meaning" (Gutt 1992:58). In the relevance theoretical framework, "unnaturalness is regarded as inconsistency with the principle of relevance" (Gutt 1992:73). This means that if a translated pun preserves the linguistic features of the original, yet is thought unnatural by the target audience, it has not been rendered successfully. In a situation where this might happen, a translator should always consider the audience's optimal relevance as priority, and decide whether preserving the sound of the pun she/he will sacrifice the meaning of the entire phrase (Gutt 2000b).

\subsection{Ways of Translating Chinese xiehouyu}

As discussed in Section 3.2.3, Gutt (1992, 2000b) suggests two approaches for translation using the relevance theoretical framework: direct and indirect. Where xiehouyu are concerned, the direct translation approach is for people who have a prior knowledge of Chinese language and culture, while the indirect approach is for people who have no such knowledge. There is more than one way of translating a text indirectly; a number of different indirect renderings may be possible depending on the needs of the target readers.

\subsubsection{Direct and Indirect}

Direct translation aims to achieve complete interpretive resemblance with the original. In the direct translation approach, the implicit information of metaphors is preserved as much as possible in the target text, with the least possible explication. This is to eliminate the danger of distorting the original meaning through explication and to encourage the audience to explore the rich contextual effects of the original (Gutt 2000a). In direct translation of xiehouyu, it is recommended that the metaphor be preserved in its implicit form in order to guide the audience using the contextual assumptions "envisaged by the original" so they can obtain the interpretation of the source text (Gutt 1992:67). Background information is provided for those xiehouyu which contain allusions or culturally specific items. Consequently, the shared cognitive environments between the source and the target audience will be increased and as a result the translated xiehouyu can yield adequate contextual effects and achieve optimal relevance to the target audience. 
When translating puns, the ideal is to convey the intended meaning and at the same time preserve the punning sense in the translation. However, in practice translators often find they can "achieve a higher degree of resemblance but only at the cost of a decrease in overall relevance because it involves an increase in processing effort that is not outweighed by gains in contextual effects" (Gutt 2000a:118). The rule of thumb is that translated wordplays should never hinder communication. In translating the punning type of xiehouyu, translators should attempt to preserve the implicit nature of the metaphor as well as the wordplay. However, this must be consistent with the principle of relevance. If the meaning and the punning sense cannot be both preserved, the translator may need to preserve the meaning and sacrifice the play on words.

In contrast, indirect translation is for a target audience who does not share a cognitive environment with the original. In the case of Chinese xiehouyu translation, it is for people with no knowledge of Chinese language or culture. With such a target audience in mind, translators tend to explicate implicit information and remove any ambiguities (such as puns and other wordplays) that might increase the processing effort without producing extra contextual effects as a reward. The goal of indirect translation is to maximise the contextual effects of the translated text, as well as to reduce any unnecessary processing effort the audience might spend to achieve optimal relevance. This approach "entitles the audience to start from the most accessible contextual information, looking for consistency with the principle of relevance in usual fashion" (Gutt 1992:64).

\subsubsection{Comparative Analysis}

In this section, a number of xiehouyu examples with sample contexts will be discussed using both direct and indirect approaches. Within the indirect approach, two ways will be presented, with and without substitution of the appropriate metaphor, to examine the particular interpretive resemblance each one offers and indicate for what kind of audience each might be appropriate. In this section, the sample contexts are cited from Bao and Bao (2001), and parts of the translations are based on Bao and Bao (2001).

$\begin{array}{lccc}\text { 正月 } & \text { 十五 } & \text { 貼 } & \text { 門神 } \\ \text { Zhengyue } & \text { shiwu } & \text { tie } & \text { menshen } \\ \text { first lunar month } & \text { the fifteenth day } & \text { paste } & \text { the Door God }\end{array}$

$\begin{array}{lllc}\text { - 晚了 半 } \text { 月 } & \text { 啦! } \\ \text { - wan le ban yue } & \text { la! } \\ \text { late particle half } & \text { month } & \text { interjection }\end{array}$

Pasting up pictures of the Door Gods on the fifteenth day of the first lunar month, half a month late. 


\section{(4.10) Context: \\ 等 他們 趕來 增援 時, 已是月 \\ Deng tamen ganlai zengyuan shi, yi shi 'Zhengyue wait they arrive reinforce time already be the first lunar month 十五貼 門神 - 晚 了 半月 啦! ’ shiwu tie menshen - wan le ban yue la!' the fifteenth day paste the Door God late particle half month interjection (Feng Zhi: Armed Working Team Behind the Enemy Line, cited in Bao 2001).}

Direct Translation: They came too late and past the time for rescue, just like pasting up pictures of the Door Gods when the Chinese New Year is already half a month past.

Note: The Chinese paste up the pictures of the two Door Gods on the first day of the Chinese New Year. This is done as a way to avert evil and protect the entire household throughout the year.

Indirect Translation: When they arrived, it was too late for a rescue.

Substitution of metaphor: But they were too late, like shutting the door after the horse had bolted.

In the direct translation, the metaphoric linguistic form is preserved without explication. This is to give the target audience the most complete and authentic resemblance of the original xiehouyu. Although the metaphoric linguistic form is changed to a simile in translation, the translator tries to preserve the resemblance of the translated text to the original as much as possible. As a result, the target audience may still have access to the most complete and authentic contextual information of the original xiehouyu.

It is presumed that the target audience may not know the specific custom of pasting the pictures of the two Door Gods on the very first day of the Chinese New Year. Therefore, an explanatory note is provided to help the target audience understand the Chinese custom, so s/he can interpret this xiehouyu by using correct contextual assumptions and be able to infer the intended implicature and achieve optimal relevance. 
In contrast, the indirect translation explicates the intended meaning 'too late' without preserving the original metaphorical linguistic form, or mentioning the custom of putting up two Door Gods pictures. This is because the intended implicature 'it's too late' of this xiehouyu is relatively strong and quite straightforward to the source audience. A total explication is adopted, because it is considered the contextual effects of the original xiehouyu do not outweigh the extra processing effort spent by the target audience.

In (4.10), it is possible to replace the Chinese metaphor with an appropriate English metaphor shutting the door after the horse has bolted. It makes the translation more vivid and easier to understand by the target audience.

$$
\begin{array}{llll}
\text { 徐庶 } & \text { 进 曹 } & \text { 營 } & - \text { 言 不 發 } \\
\text { Xu Shu jin Cao } & \text { ying }- \text { yi yan bu fa } \\
\text { proper name enter surname camp one word not utter } \\
\text { Xu Shu entering Cao's camp, without saying a word. }
\end{array}
$$

(4.12) Context:

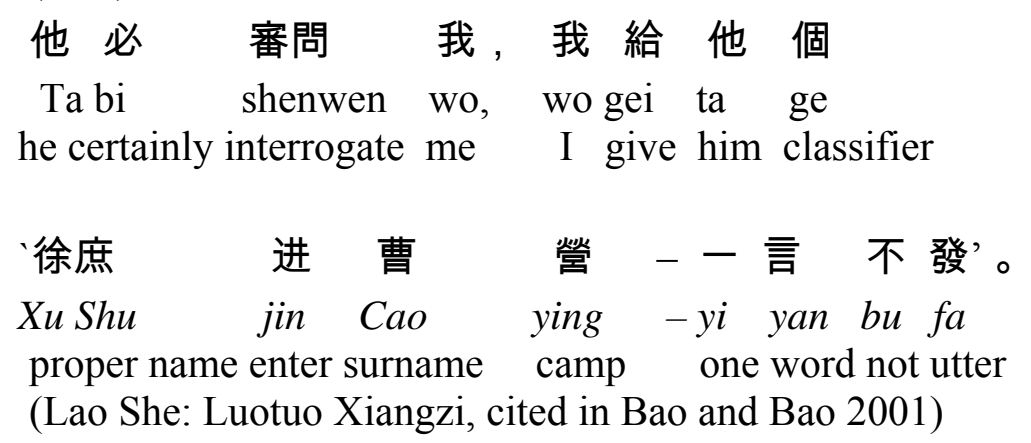

Direct Translation: He's sure to interrogate me, but I will be like Xu Shu entering Cao's camp, without saying a word.

Note: This is a story from The Romance of Three Kingdoms. Xu Shu was tricked by Cao Cao's forged letter and left Liu Bei's service. As a result, $\mathrm{Xu}$ 's mother committed suicide because of the shame her son brought to the family. Xu took a vow not to speak to Cao Cao ever again.

Indirect Translation: He's sure to interrogate me, but I won't say a word.

Substitution of metaphor: He's sure to interrogate me, but I'll keep my mouth shut. 
In the direct translation, the metaphor is again changed to a simile, which preserves a higher degree of interpretive resemblance of the translated text than indirect translation does. In case the target audience do not know the story of $\mathrm{Xu}$ Shu, an explanatory note is provided to help the target audience reach the intended implicature.

In comparison, the indirect translation substitutes another metaphor, 'keep my mouth shut' which has the same intended meaning as 'not to say a word'. This metaphor, although different in linguistic form, derives adequate contextual effects and conveys the same intended implicature. The audience will spend the least processing effort to achieve optimal relevance.

豬八戒 吃 人參果 - 全 不知 滋味
Zhu Bajie chi rensenguo - quan bu zhi ziweir
Proper name eat ginseng fruit totally not know taste
Zhu Bajie eating ginseng fruit, doesn't know what the taste is like.

(4.14) Context:

你 這 奴才! ‘豬八戒 吃人參果 - 全 不 知滋味'!

Ni zhe nucai! 'Zhu Bajie chi rensenguo - quan bu zhi ziweir'! you this servant Proper name eat ginseng fruit totally not know taste

\section{說 得 好 容易! 是 雪片糕! \\ Shuo de hao rongyi! Shi xuepiangao! speak particle very easy be walnut wafer! (The Scholars 65, cited in Bao and Bao 2001)}

Direct Translation: Silly servant! You are like Zhu Bajie who swallows the ginseng fruit without even realising its taste. You just simply ate it all! This is a walnut wafer, for god's sake!

Note: Zhu Bajie (Pigsy) is a famous character in the novel entitled Journey to the West. He used to be a Divine General of heaven but was punished and reincarnated as a pig. Therefore, he was gluttonous like a pig. One day he stole a precious ginseng fruit from an immortal's orchard. He quickly swallowed the fruit and spared no time to enjoy its unique taste.

Indirect translation: Silly Servant! You don't know how precious this food is. You just simply ate it all! This is a walnut wafer, for god's sake! 
In the direct translation, the famous character metaphor is also changed to a simile to preserve a higher degree of interpretive resemblance of the translated text and the contextual effects of the original xiehouyu. Again, the target audience might not be familiar with the story of Pigsy, so a note is provided to help the target audience reach the intended implicature.

In comparison, the indirect translation adopts a total explication, because the metaphor has a strong implicature of 'being ignorant about the value of something'. The assumption here is that preserving the original metaphor may not offer adequate contextual effects to the target audience and cost too much processing effort.

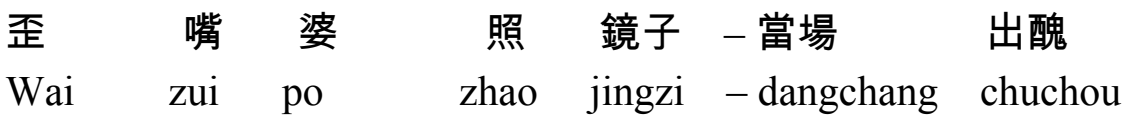
crooked mouth old woman look into mirror on the spot become a laughing stock An old woman with a crooked mouth looks into the mirror, her ugliness is exposed on the spot (this is a pun for showing one's imperfection or losing face).

\section{(4.16) Context:}

\section{王 經理 昨天 在 記者會素本的}

Wang Jingli zuotian zai jizhe hui shang, yuanben biaoxian de Wang Manager yesterday at press conference particle initially do particle 不錯。可是 當 有 位 報社 記者提 個 bucuo, keshi dang you wei baoshe jizhe ti ge good but when have classifier newspaper office journalist raise classifier 簡單 的 問題 把 他 給 問 住 的時候, 他 就 jiandan de wenti ba ta gei wen zhu de shihou, ta jiu simple particle question particle him particle ask particle particle time he then '歪嘴 婆照鏡子 - 當場出醜' Wai zui po zhao jingzi - dangchang chuchou crooked mouth old woman look into mirror on the spot become a laughing stock An old woman with a crooked mouth looks into the mirror, her ugliness is exposed on the spot (this is a pun for showing one's imperfection or losing face.

(cited in Bao and Bao 2001)

\section{Direct Translation:}

Manager Wang was doing quite well initially at the press conference yesterday. But when a newspaper journalist asked him a simple question to which he was not able to give an answer, he was immediately like an old woman with a crooked mouth looking into the mirror- her ugliness was exposed on the spot. 
Note: Chuchou (the ugliness is exposed) is a pun for 'showing one's imperfection or losing face'.

Indirect Translation:

Manager Wang was doing quite well initially at the press conference yesterday. But when a newspaper journalist asked him a simple question to which he was not able to give an answer, he was disgraced on the spot.

Substitution of metaphor:

Manager Wang was doing quite well initially at the press conference yesterday. But when a newspaper journalist asked him a simple question to which he was not able to give an answer, he got egg on his face.

This xiehouyu is a homographic type, where chuchou has two readings: 'ugliness is exposed' and 'being disgraced'. The audience determines the intended pun meaning of the homographic phrase by reference to the context. In the direct translation, the descriptive metaphor is preserved so the target audience may have the most full and authentic implicatures of the original. Because of linguistic differences, the pun chuchou 'the ugliness is exposed' and 'showing one's imperfection or losing face' cannot be preserved. This is compensated for through the note.

In contrast, the indirect translation simply translates the xiehouyu as 'disgraced on the spot'. This is because if metaphor and pun were preserved, the target audience might spend unnecessary effort to infer the intended meaning. There would be a high chance of failing to achieve communication success.

The English metaphor substituted for the Chinese one in (4.16) is having egg on his face, which is suitable for use in a situation where the target audience is English-speaking. It would cost less processing effort and increase the chances of achieving better contextual effects because of the audience's familiarity with the English metaphor.

\section{CONCLUSIONS}

This study examines the translation of Chinese xiehouyu within the relevance theoretic framework, based on translation examples produced by both the direct and the indirect approach with and without the substitution of an appropriate metaphor. It argues that while relevance theory is effective in both approaches, it is particularly important for indirect translations, where there are various ways of translating a xiehouyu with regard to what meaning aspects of the original the 
target audience will find relevant. Substitution of metaphor is illustrated as an indirect approach. Although a match-up metaphor in the target language may not always be available, whenever possible the strategy of substituting metaphors should be utilised to maximise the contextual effects and minimise the processing effort, as it is a most effective way to achieve optimal relevance.

With translation as an instance of interpretive use, the success of a translation depends on the optimal achievement of relevance. Equally importantly, the translator has to pay attention to the kind and degree of interpretative resemblance which the audience expects. That is to say, a translator should take the target audience's cognitive environment into account and choose the most suitable approach to guide the audience to achieve optimal relevance.

The significance of Gutt's relevance theoretical framework is its explanatory power, which meets the needs of translators. Gutt's model provides a platform to describe and explain translation as a type of communication. While Gutt's approach does not advocate specific strategies of translating, it does help in explaining communicative effectiveness and leads the translator to select a particular strategy for its effectiveness. It provides new insights into the process of translation by showing that the general principles of communication - the principles of relevance - also apply to translation.

This study pioneers in applying the relevance theoretical framework to Chinese xiehouyu translation. Further comparative studies on ways of indirect translating of Chinese xiehouyu, depending on different target audience groups and situations (e.g. young, old, informal and formal), would contribute greatly to the development of translation research in general. Further research on the humorous aspect of Chinese xiehouyu would also provide valuable insights, since humour plays a significant role in these sayings.

\section{Notes}

1

The authors are indebted to Ernst-August Gutt and the anonymous reviewers, for their valuable suggestions which have been incorporated into the final version. We would also like to thank Anne Guan and the editor of the article for their skilled assistance in the revision of this article.

2 All Chinese examples are presented in the order of Chinese characters followed by Pinyin (the Chinese phonetic alphabet, invented for representing pronunciation of Chinese characters). English translations are given in two layers: interlinear gloss and then translation.

3 "New Year" here means "Chinese New Year". Chinese people have a custom of visiting each other during the Chinese New Year. They intend to wish people good luck and a prosperous life in the coming year. This custom is called bainian (拜年, wish someone a Happy New Year).

${ }^{4}$ Lü Dongbin is one of Baxian (八仙, the Eight Taoist Immortals). He often helps people who are in distress or desperately in need. Therefore Lü is a very popular figure in Chinese mythology, representing "Mr. Good" (Sun 1981). 
Inferential Model of Communication: In this model, inference plays an important role as the basic factor of communication. The audience infers the communicator's intended meaning rather than simply encoding and decoding messages as suggested in the code model (Sperber and Wilson 1986, 1995).

Stimulus is a phenomenon designed to achieve cognitive effects (Sperber and Wilson 1986: 153).

7 Cognitive environment: consists of all the facts an individual is capable of representing in his mind and of accepting as true, or probably true. The sources of this information can be perception (seeing, hearing, etc.) memory, or inference (Gutt 1992:22).

${ }^{8}$ Sperber and Wilson $(1986,1995)$ claim that in relevance theory, there are two psychologically distinct modes of using language: a. the descriptive use, an utterance intended to be taken as a true of a state of affairs in some possible world; b. the interpretive use, an utterance intended to represent what someone said or thought.

9 Communicative clues: the clues that guide the audience to the interpretation intended by communicators (Gutt 2000b).

The Story of the Stone is a Chinese classical novel written by Cao Xueqin. Translations were made by David Hawkes and John Minford in the 1980s.

The Scholars is a Chinese classical novel written by Wu Jingzi. Yang Hsieh Yi and Gladys Yang translated it into English in 1957.

Water Margin is a famous Chinese classical novel written by Shi Nai'an, translated by J. H. Jackson in 1937.

It is used to describe a situation where one has only two options: move forward or fall behind.

${ }^{14}$ Poetic effect: the peculiar effect of an utterance which achieves most of its relevance through a wide array of weak implicatures (Sperber and Wilson 1986:222).

\section{References}

Bao, H \& Bao A. 2001. Translation in Cultural Context (實用文化翻譯學). Shanghai: Shanghai Kexue Poji Press.

A Chinese-English Dictionary. 1978. ed. by Beijing Foreign Language Institute. Beijing: Commercial Press.

Chen, W. D. 1962. Introduction to Rhetoric. Shanghai: Wenyi Publishing Company.

Cheung, H. N. 1982. A Study of Riddle Expressions in Cantonese. Qinghua Xuebao (Taiwan) Vol. 14. No 2. 51-103.

Fawcett, P. 1997. Translating and Language: Linguistic Theories Explained. Manchester: St. Jerome Publishing.

Feng, C. H. 2001. The Bible of Techniques for English to Chinese Translation. Taipei: Lighthouse Publishing Company.

Frawley, W. 1992. Ernest-August Gutt, Translation and Relevance: Cognition and Context (book review). Journal of Linguistics Vol. 28. No. 2. 516-519.

Giles, H. A 1967. A Chinese-English Dictionary. Shanghai and London: Chengwen Publishing. Grice H. P. 1975. Logic and Convention. Oxford: Oxford University Press.

Gutt, E. A. 1990. A Theoretical Account of Translation-Without a Translation Theory. Retrieved from: http://cogprints.ecs.soton.ac.uk/archive/0002597/01/THEORACC.htm, on 25th Dec, 2002.

Gutt, E. A. 1991. Translation and Relevance: Cognition and Context. Oxford: Blackwell.

Gutt, E. A. 1992. Relevance Theory - A Guide to Successful Communication in Translation. Dallas Summer Institute of Linguistics and New York: United Bible Societies.

Gutt, E. A. 1998. Pragmatic Aspects of Translation: Some Relevance-Theoretic Observations. In: Hickey, L. (ed.) The Pragmatics of Translation. Clevedon: Multilingual Matters. 41-53.

Gutt, E. A. 2000a. Translation and Relevance: Cognition and Context. Manchester: St. Jerome Publishing (2nd edition).

Gutt, E. A. 2000b. Translation as Interlingual Interpretive Use. In: Venuti. L. (ed.) The Translation Studies Reader. London: Routledge. 376-396.

Hatim, B. 1998. Relevance in Translation. In: Baker, M. (ed.) Encyclopaedia of Translation Studies. London: Routledge, 179-183. 
Hymes, D. 1992. Review of Gutt 1991. Language in Society Vol. 21. No. 2. 316-317.

Lefevere, A. 1992. Translating Literature Practice and Theory in a Comparative Literature Context. New York: Modern Language Association of America.

Malmkjær, K. 1992. Review: Translation and Relevance: Cognition and Context by E. A. Gutt. Mind and Language Vol. 7. No. 3. 298-309.

Mathews, R. H. 1943. Mathew's Chinese-English Dictionary. Cambridge: Harvard University Press (Revised American edition).

Rohsenow, S. J. 1991. A Chinese-English Dictionary of Enigmatic Folk Similes (Xiehouyu). Arizona: The University of Arizona Press.

Salkie, R. 1991. Deviations from the Literal, Review of Ernest-August Gutt. Times Higher Education Supplement 26.7.1991.

Shan, J. Q. 2001. Techniques in Chinese to English Translation. Beijing: Foreign Language Teaching and Research Publishing Company.

Sperber, D. \& Wilson, D 1986. Relevance: Communication and Cognition. Oxford: Blackwell.

Sperber, D. \& Wilson, D 1995. Relevance: Communication and Cognition. Oxford: Blackwell (2nd edition). Steelman, D. L. 1990. Chinese Riddle-Phrases Vols. 1-5. Taipei: The Overseas Chinese Library.

Sun, C. C. 1981. As the Saying Goes. Queensland: University of Queensland Press.

Wen \& Zhou 1999. Study of Twenty Century Chinese Vernacular Folk Sayings. Xanxi: Xinhua Publishing Company.

Wendland, E. R. 1996. A Review of 'Relevance Theory' in Relation to Bible Translation in South-Central Africa [Part I]. Journal of Northwest Semitic Languages Vol. 22, No. 1. 91-106.

Wickler, W. K. \& Van Der Merwe, C. H. J. 1993. Training Tomorrow's Bible Translators: Some Theoretical Pointers. Journal of Northwest Semitic Languages Vol. 19. No. 19. 41-58.

Yu, G. Y. 2000. Twenty Century Applied Chinese Studies. Xanxi: Xuhai Publishing Company. 